\title{
?19 institute
}

TI 2021-029/VIII

Tinbergen Institute Discussion Paper

\section{Pcoins for parking: a field experiment with tradable mobility permits}

\author{
Devi Brands ${ }^{1}$ \\ Erik Verhoef ${ }^{1}$ \\ Jasper Knockaert ${ }^{1}$
}

${ }^{1}$ Department of Spatial Economics, Vrije Universiteit Amsterdam, the Netherlands 
Tinbergen Institute is the graduate school and research institute in economics of Erasmus University Rotterdam, the University of Amsterdam and Vrije Universiteit Amsterdam.

Contact: discussionpapers@tinbergen.nl

More TI discussion papers can be downloaded at https://www.tinbergen.nl

Tinbergen Institute has two locations:

Tinbergen Institute Amsterdam

Gustav Mahlerplein 117

1082 MS Amsterdam

The Netherlands

Tel.: +31(0)205984580

Tinbergen Institute Rotterdam

Burg. Oudlaan 50

3062 PA Rotterdam

The Netherlands

Tel.: +31(0)10408 8900 


\title{
Pcoins for parking: a field experiment with tradable mobility permits*
}

\author{
Devi K. Brands $s^{\dagger}$ Erik T. Verhoef $\&$ Jasper Knockaert ${ }^{\dagger}$
}

\begin{abstract}
With congestion being one of the most important externalities in transportation, it remains important to investigate effective and politically feasible solutions for it. We have conducted an 8-week experiment with tradable mobility permits, specifically applied to the use of parking facilities at a Dutch employer. We combine actual mobility behaviour with trading behaviour and survey responses of participants and non-participating employees of the same company. We have analysed the choice to participate in a voluntary experiment, and the behavioural response to tradable permits. Our results provide suggestive evidence that active participants do adjust their behaviour as intended. Furthermore, participation takes less time than people anticipate, and permits are viewed as a fairer and better functioning alternative to paid parking.
\end{abstract}

\section{Introduction}

In recent decades, congestion on the road network in urban areas has steadily increased (Cohn, 2019). Covid-19 has temporarily changed this, but after the pandemic is over, congestion is expected to cause problems such as time losses and extra air pollution again. To keep cities accessible and liveable in the future, it is therefore necessary to find feasible solutions to traffic congestion. One of the theoretically and empirically proven ways to effectively reduce congestion is to introduce a dynamic toll (see e.g. Vickrey, 1973; Arnott et al., 1993; Leape, 2006), such that traffic is spread more evenly over time and space. However, charging for driving during rush hour in a particular zone, or on a particular road or motorway, has the disadvantage that there is often little social or political support for it. The reason for this is that it is usually seen as additional taxation (Lindsey and Santos, 2020). This explains why this policy option is used very little, despite its proved effectiveness, while congestion is a problem in almost all urban areas worldwide. Transport economists have therefore looked for an effective and politically feasible policy alternative. Tradable permits are a promising option in this respect, receiving increasing attention in the transport literature since Verhoef et al. (1997).

Nie (2012) provides a theoretical examination of the effects of transaction costs in auction and negotiation markets for mobility credits. The results indicate that transaction costs can divert the system from the desired equilibrium, especially in the negotiated

\footnotetext{
${ }^{*}$ We would like to gratefully acknowledge ANWB and Innovactory in general, and Geordie Kooiman and Stefan Bollars in specific, for the collaboration in organizing the experiment. This work is supported by funding of VerDuS' Smart Urban Regions of the Future (SURF) program as part of the U-SMILE project 438-15-176, and by the European Union's Horizon 2020 program as part of IP-SUNTAN project 5597288, which is gratefully acknowledged. Email address: Devi Brands (corresponding author), d.k.brands@vu.nl

${ }^{\dagger}$ Department of Spatial Economics, Vrije Universiteit Amsterdam, the Netherlands.

${ }^{\ddagger}$ Corresponding author. Email: d.k.brands@vu.nl
} 
market. Yang and Wang (2011) build a model to investigate link flow patterns in the equilibrium, when introducing travel credits to the system. They show that the most desirable link flow patterns can be accomplished by a combination of the appropriate distribution of credits and the right link-specific rates. This work is extended to a model with heterogenous users in terms of value of time in Wang et al. (2012), with a user-class based credit distribution. Xiao et al. (2013) investigate a system with a time varying credit charge at the bottleneck, with identical and non-identical users, and show that the optimal credit charging scheme is Pareto-improving. Tian et al. (2013) build on this work by introducing a model with heterogeneous users and modal split. Their results show that, when the system optimum is achieved, the system is always Pareto-improving. Akamatsu and Wada (2017) examines the properties of a tradable permit system in a general network, and make a comparison with congestion pricing. They demonstrate that tradable permits can have advantages over congestion pricing when demand information is not perfect, while both are equivalent under perfect information. de Palma et al. (2018) also compare tradable credits (referred to as tokens) with pricing, using a theoretical framework. Their numerical experiments demonstrate that both measures are equivalent if pricing and permits can be fully adapted to demand and supply shocks. They argue that, in the presence of uncertainty, and strongly convex congestion costs, tokens outperform pricing. Xiao et al. (2019) build a model with cyclic tradable credits that do not expire and do not require new rounds of credit distribution. They investigate the influence of tradable credits on social equity and demonstrate that equity among commuters can be improved with a tradable credit system compared to several traditional tolling schemes. Bao et al. (2019) show that, for particular models of congestion, tradable credit schemes may not lead to an equilibrium that is unique, which can be detrimental to the social welfare effects of such a scheme.

Eventhough tradable permits in transportation settings have recently received a considerable amount of attention in the literature, of which important theoretical contributions have been discussed above, only very few experiments have been conducted so far. Aziz et al. (2015) conducted an online experiment with a carbon allowance scheme for personal travel, including a market where the allowances could be traded. Their results suggest that middle and low income groups are highly sensitive to such an incentive for their non-work trips, while high income groups react less, especially for their work related trips. Tian et al. (2019) also used an online experiment to test behavioural effects in tradable mobility credit schemes. They observe loss aversion, an immediacy effect and a learning effect in their data. They show that their tradable mobility credit scheme is fairly efficient. Brands et al. (2020) introduced a market design for experiments with tradable permits and succesfully tested it with a lab-in-the-field experiment. Geng et al. (nd) did a first experiment with actual behaviour in a setting with congestion, the on campus canteen of the BJTU in Beijing during breakfast time, and show that students did reduce rush hour breakfasts when facing the incentive of tradable permits.

This paper contributes to the literature in two ways. Firstly, after a lab-in-the-field experiment with tradable mobility permits, and the breakfast experiment among Chinese students, it is time to test the functioning of a permit scheme in a field experiment with real mobility behaviour. To the best of our knowledge, we are the first to conduct such an experiment. Secondly, our paper illustrates that smart financial incentives, specifically in the form of tradable permits, can be used by employers as a tool to allocate scarce parking space over employees.

We use the market design proposed in Brands et al. (2020) and provide evidence of its functioning, and insights into participants attitudes towards tradable permits in such a 
setting. Our experiment has been conducted at the $\mathrm{ANWB}^{1}$ headquarters in The Hague (the Netherlands) in late 2019 and early 2020, with the measurements ending before Covid-19 could have affected mobility patterns through lock-down measures or otherwise. The experiment lasted 8 weeks, with a total of 65 participants who voluntarily signed up to participate. We combine data on parking behaviour, trading behaviour and stated preference data from surveys among both participants and non-participating employees of ANWB. We analyse the choice to participate and find no clear evidence of self selection in terms of socio demographics. We do find a correlation between attitudes and the decision to participate. The collected data furthermore provides an indication that participants reacted rationally to the incentive of tradable permits and traded rationally as well. Our results suggest that those who participated actively in the trading of permits, also reacted to the incentive by parking approximately $15 \%$ less. Furthermore, the results indicate that those who did not trade (or hardly traded) their permits did not react to the incentive. A plausible explanation for this is that these more passive participants may have signed up with the intention to collect the guaranteed non-negative final reward that would result from participation when not changing behaviour at all.

The remainder of this paper is structured as follows. Section 2 provides an overview of the experimental set-up. An elaborate discussion of the collected data is presented in Section 3. Analyses of these data and results are discussed in Section 4. Finally, Section 5 concludes and provides suggestions for future research.

\section{Experimental set-up}

We have conducted the experiment at the headquarters of ANWB in The Hague, the Netherlands. The experiment has been done in close collaboration with ANWB and technology partner Innovactory. The latter designed and programmed the application that was used for the experiment. This application was entirely consistent with the market design presented in Brands et al. (2020), but had a more professional look than the one used in their empirical implementation and was of course also targeted to the specifics of the current experiment. We have conducted multiple surveys using Survey Gizmo. Besides pre- and post-experiment surveys, we have collected travel diaries, parking movements at the headquarters, and data on trading of the parking permits. The experiment comprised a total of 8 weeks, with a 2-week Christmas break in the middle, lasting from the end of November 2019 until the end of January 2020. Finally, we have also conducted a survey among employees of the ANWB who did not participate, a few weeks before the first Covid-19 lock-down was put in place in the Netherlands. The remainder of this section describes the design of the experiment.

\subsection{Recruitment and assigning to groups}

Users of the ANWB parking facilities could voluntarily sign up to participate in the experiment and were recruited using flyers, and managers were asked to promote the experiment among members of their team. A total of 65 employees signed up, coming from different departments of the ANWB. Only employees who worked at the ANWB headquarters could sign up. Data on parking movements at the headquarters in three normal working weeks pre-experiment, the reference period, assured that we knew how often participants came by car. The participants were then randomly divided into two groups of approximately

\footnotetext{
${ }^{1}$ ANWB is the main travellers association in the Netherlands, with a focus on car users.
} 
Figure 1: Groups and trading conditions

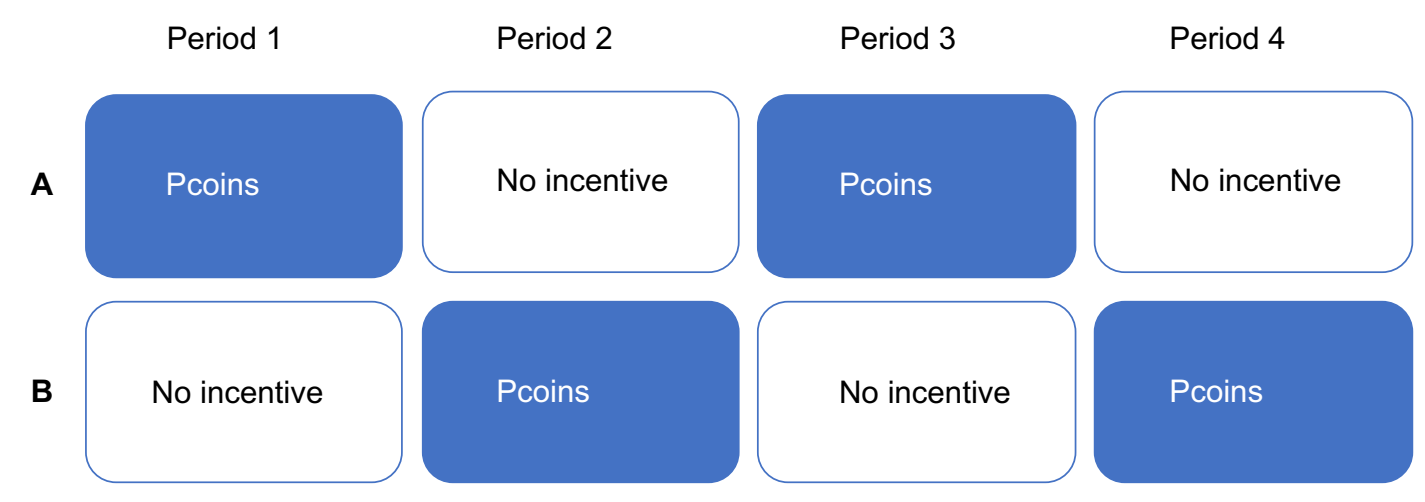

equal size, referred to as group $A$ and group $B$. These two groups were comparable in terms of the average number of times per week participants parked at the headquarters.

Both groups faced two two-week trading periods during which parking at the headquarters cost one Pcoin. This was either during period 1 and 3 or during period 2 and 4 , depending on the group to which participants were assigned. These two trading periods were alternated with a two-week control period, during which no Pcoins were required to park, thus resulting in a total duration of $4 * 2=8$ weeks. A schematic representation of the groups and trading conditions is provided in Figure 1.

\subsection{Trading periods}

During the trading periods, which are the treatment periods of the experiment, parking at the ANWB headquarters between 6:00 am and 5:00 pm on workdays cost one tradable parking permit, a Pcoin. Parking outside this time window, or during the no incentive periods, did not cost anything. Pcoins could be traded within the developed application at the then current permit price, which varied over time depending on scarcity conditions (see Section 2.3 for more details). All participants received a trading budget once, at the beginning of the experiment, which could be used during the whole experiment. The remainder of this budget was paid out in real money at the end of the experiment. Participants knew that they would receive the remainder of their budget, providing them with an incentive to trade Pcoins smartly and reduce the number of times they used the parking facilities during the trading periods. All participants were allocated a number of Pcoins at the start of the week, if they were part of the incentive group in that specific week. The number of permits participants received was based on the number of days per week they work according to their contract. Participants subsequently decide whether to use (some of) their Pcoins for parking or to sell them and earn extra money; or, to buy additional Pcoins if so desired. The initial number of permits participants received per week varied from 0 to 2 .

The permit market was designed to reduce the number of parking movements of the trading participants per week to a level of approximately $80 \%$ of the parking movements in the reference weeks before the start of the experiment. The total number of permits distributed per week was brought as close as possible to this $80 \%$. To encourage trading, some of the trading participants received relatively more Pcoins, while others received relatively fewer Pcoins. Participants who received relatively fewer Pcoins were compen- 
sated by receiving a higher monetary starting budget. The starting budgets were chosen such that participants would have enough money to buy permits against the maximum permit price to park each of their working days during the experiment. This ensured that participants would not drop out due to no longer having an incentive to continue their participation. However, as we will see below, it may also have given an incentive to sign up and not actively participate in the experiment, just waiting for some amount of money to come in after the project. Starting budgets varied from 40 euros to 160 euros.

\subsection{Market for permits}

We have used the market design for tradable permits introduced and described extensively in Brands et al. (2020), and previously used in Geng et al. (nd). In this design, participants trade directly with a bank, which uses a simple algorithm to adjust the price for permits. The design ensures that the price increases (decreases) if the sum of currently owned and currently used permits is higher (lower) than a predetermined policy target. The policy target in our case was to have a reduction in parking movements of approximately $20 \%$, to a level of $80 \%$ of the movements in the reference period. The advantage of this design is that trading permits is easy and takes little effort for participants. The smart-phone application that can be used for trading shows a single prevailing permit price against which participants can buy additional permits or sell some of their permits whenever they prefer during the trading weeks. To prevent undesirable speculation, a number of safeguards were built in. For instance, a participant could not own more permits than the number of working days that remained that week. If, at a certain moment, one held more permits than the number of remaining working days, an automated sale took place at the then market price. Conversely, if participants parked without owning a permit, one was automatically bought at the then current price. Registration of parking movements took place through automatic license plate registration at the entrance to the car park.

\section{Data}

We have collected data from multiple sources. Socio demographics and attitudes towards a range of statements have been collected using Survey Gizmo. We have done so for participants in a pre- and a post-experiment survey. Non-participants have been surveyed after the experiment had ended. Travel diaries of each of the weeks during the experiment have been collected using the same platform. Parking movements of participants at the headquarters have been provided to us by ANWB. We received these for four weeks prior to the experiment, all weeks of the experiment, and four weeks after the experiment had ended. ${ }^{2}$ Trading behaviour of the participants was tracked in the developed application. The remainder of this section provides an overview of the collected data and a initial inspection of the patterns in the data.

\subsection{Descriptive statistics}

Table 1 provides some descriptive statistics of participants and non-participants. It shows that participants and non-participants are very similar in many respects. The main difference in terms of these characteristics is car availability, which captures whether someone always has a car available. This holds relatively more often for participants, which can

\footnotetext{
${ }^{2}$ The prior and post experiment weeks both include a school holiday week, which have been excluded from calculating reference behaviour.
} 
be explained by the fact that one of the requirements for participation was that the person sometimes uses the parking facilities. Those who do not (always) have a car at their disposal are less likely to use the parking facilities and therefore to be eligible to participate. The age of participants varies from 23 to 61 , with an average of 43 . The age of non-participants varies from 23 to 65 with an average of 44 . With respect to income ${ }^{3}$, Table 1 shows that participants are slightly more strongly represented in the higher income categories.

Questions on demographics were included in the pre-experiment survey. However, not all participants completed that survey. Of all participants that parked at least once during the eight weeks of the experiment (this is the case for 56 of the 65 participants), $50 \%$ (57\%) filled out the pre-experiment (post-experiment) survey, with $41 \%$ filling out both.

Table 1: Descriptive statistics participants vs non-participants

\begin{tabular}{lrr}
\hline \hline & Participants & Non-participants \\
\hline Average age & $43 \mathrm{yr}$ & $44 \mathrm{yr}$ \\
Female & $50 \%$ & $45 \%$ \\
Higher education & $89 \%$ & $81 \%$ \\
$2000<$ Income $\leq 3500$ & $29 \%$ & $23 \%$ \\
Income $>3500$ & $50 \%$ & $44 \%$ \\
Car available & $93 \%$ & $67 \%$ \\
\hline
\end{tabular}

Table 2 provides an overview of the parking activity of participants. It displays the mean and standard deviation of the number of times participants parked at the headquarters per week. These data show that, from just looking at averages for all participants combined, the expected drop in parking movements during the trading (Pcoins) periods is not observed. The only apparent change appears to be between the post-experiment parking activity and the other three periods, with a relatively higher mean and standard deviation for the former. However, the means of these periods are statistically not significantly different from one another. We explore these data further in Section 3.3 and analyse them in Section 4.

Table 2: Parking activity of participants

\begin{tabular}{lrr}
\hline \hline & mean & st. dev. \\
\hline Pre-experiment & 1.99 & 1.25 \\
Control & 1.98 & 1.23 \\
Pcoins & 2.01 & 1.21 \\
Post-experiment & 2.06 & 1.36 \\
\hline
\end{tabular}

NB: No statistically significant difference between means

\subsection{Price development}

During the experiment, it became clear that not all 65 participants were equally active. However, the parking behaviour of inactive participants does have an influence on the price

\footnotetext{
${ }^{3}$ Respondents were asked to indicate their after tax monthly household income in euros, in three categories: below 2000; between 2000 and 3500; above 3500
} 
of Pcoins through the automated purchases for parking activities by inactive participants, causing an upward pressure on the permit price. In the recruitment, it was made clear that a participant would always end up with a positive balance and could therefore never be financially worse off. This means that there is no reason not to just sign up for the experiment and see whether you eventually end up with a reward. Because of the builtin safeguards against speculation (see Section 2.3), inactivity during trading periods can lead to automatic transactions by the system. Having a substantial group of inactive participants, who do not (or only to a limited extent) adjust their parking behaviour, leads to a higher use of Pcoins and drives the price up. This also happened in practice as can be seen in Figure 2.

Figure 2: Price development

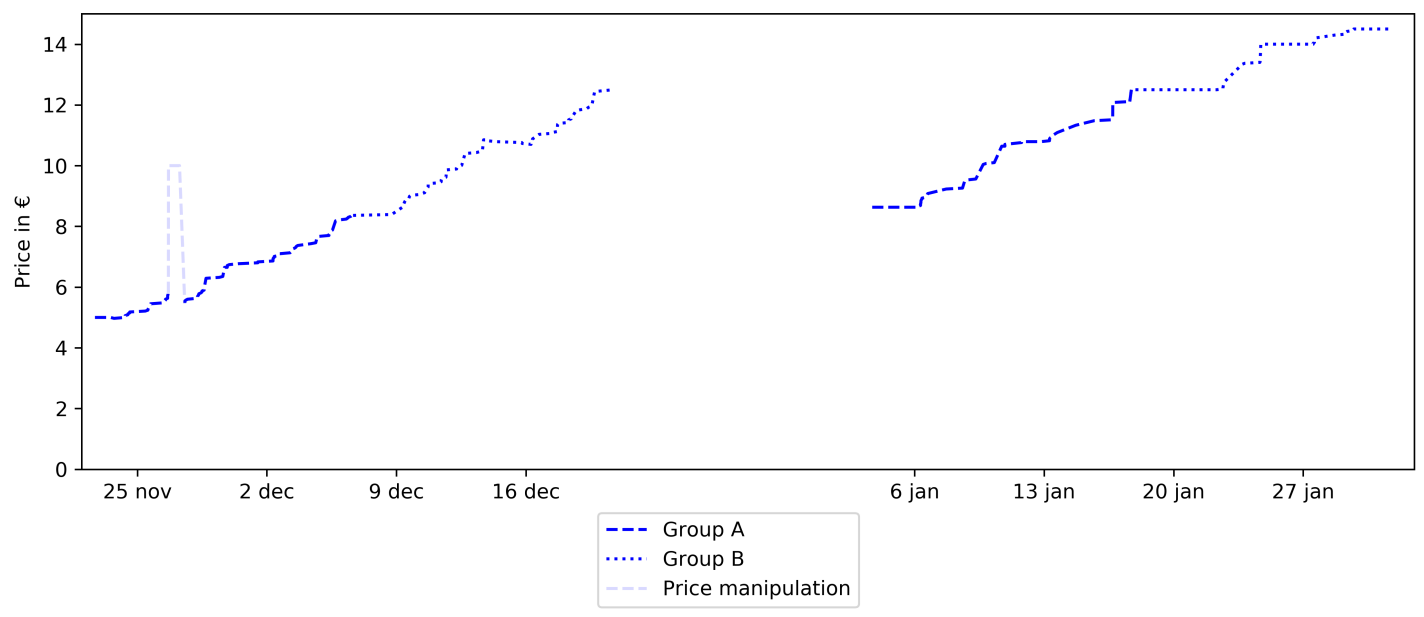

The extreme peak in the left part of the graph is an exception and was caused by manipulation of the price by two participants, which was possible because a part of the price algorithm developed earlier and as discussed in Brands et al. (2020) was missing at first in the implementation. After this was fixed, this manipulation was no longer possible. The price was reset to the level just before the price manipulation. Apart from the adjustment after this manipulation, the price constantly increased which has probably also influenced the behaviour and perception of the active participants. This constant increase is expected to have made participation less exciting than what some participants may have hoped for, as it left little room for interesting speculation opportunities.

In both trading periods, group B started with the price group A finished with in the previous week. For group A, their second trading period, after the Christmas break, started with the price set at the level it was at the end of their first trading period.

\subsection{Parking behaviour}

The main idea of the tradable parking permits is that participants would on average park less during the trading (Pcoins) weeks than they would have done otherwise. However, other factors may also affect parking behaviour considerably. It is therefore important to consider company wide patterns in parking movements in the same weeks. Figure 3 provides an overview of the total number of parking movements per week at the headquarters of ANWB. We have received these data for each of the weeks for which we have parking 
data of the participants. Figure 3 shows some variation over the weeks, but does not show trends that would considerably affect our findings on the response to the incentive. The level of total parking movements in experiment weeks (during experiment are not significantly different from those in the pre-experiment weeks (pre). The same holds for the experiment weeks relative to the post-experiment weeks (post).

Figure 3: Total number of parking movements per week

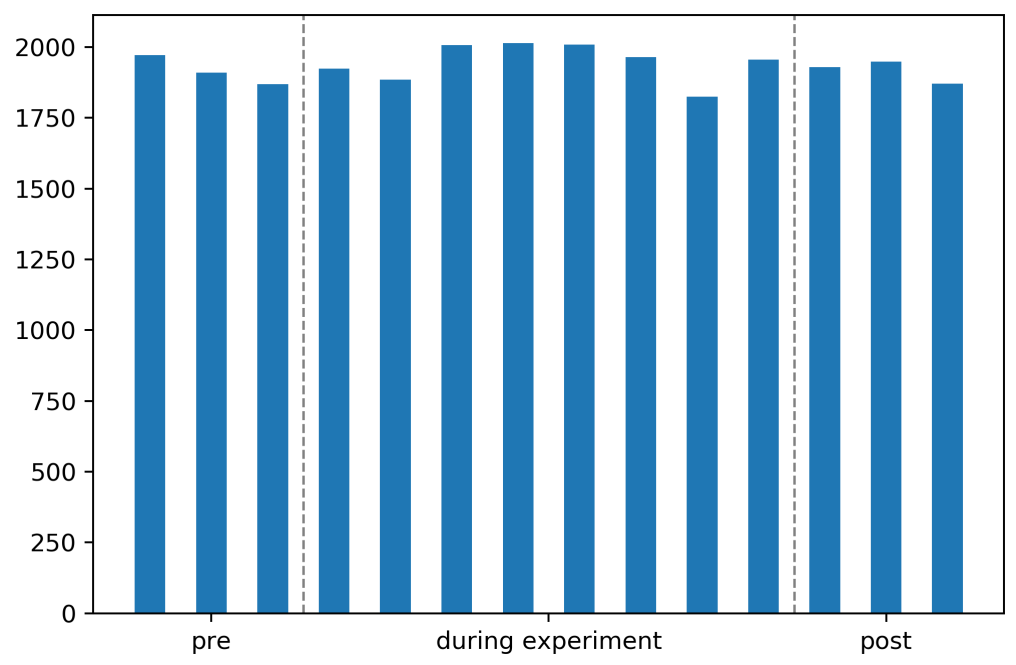

As discussed in Section 3.2, not all participants were participating actively during the experiment. Furthermore, those who do not participate actively are more likely to not change their parking behaviour. We therefore look at different definitions of being active or not, to see how the group of active participants reacted to the incentive. Figure 4 provides an overview of the reaction to the incentive for different definitions of being active, based on the percentage of the respondents' transactions that were done manually, as opposed to automatic transactions by the system (i.e., an automated purchase of a permit when parking without owning a permit, or an automated sell when the participant owns more permits at a certain moment than what is allowed). It displays the parking movements relative to the average of the pre experiment weeks. The further to the right, the greater the proportion of transactions made by the participant themselves is (rather than automatically by the system) in order to be considered active. When the definition of being active becomes stricter, in that it requires a higher percentage of active transactions, on the right side of the figure, the behavioural response to the incentive also becomes stronger; both in the trading weeks and in the weeks when people participate as a control group. Section 4.2 will investigate whether there is a significant response by the more active users, i.e. test for a significant difference between the lines in Figure 4. The fact that behaviour in control weeks moves somewhat in parallel with that in treated weeks, suggests that some participants may have decided to change their behaviour for the whole duration of the experiment (i.e. during both the control and treatment periods). This could for example be the case due to mental or scheduling reasons, e.g. because doing so means that you do not have to think about whether you are in the treatment group or not in a specific week. This is reinforced by the observation that after the experiment, parking behaviour returned to pre-experiment levels, also for active users (see Figure 5).

Figure 5 shows the difference in parking behaviour between active and passive par- 
Figure 4: Parking per activity level

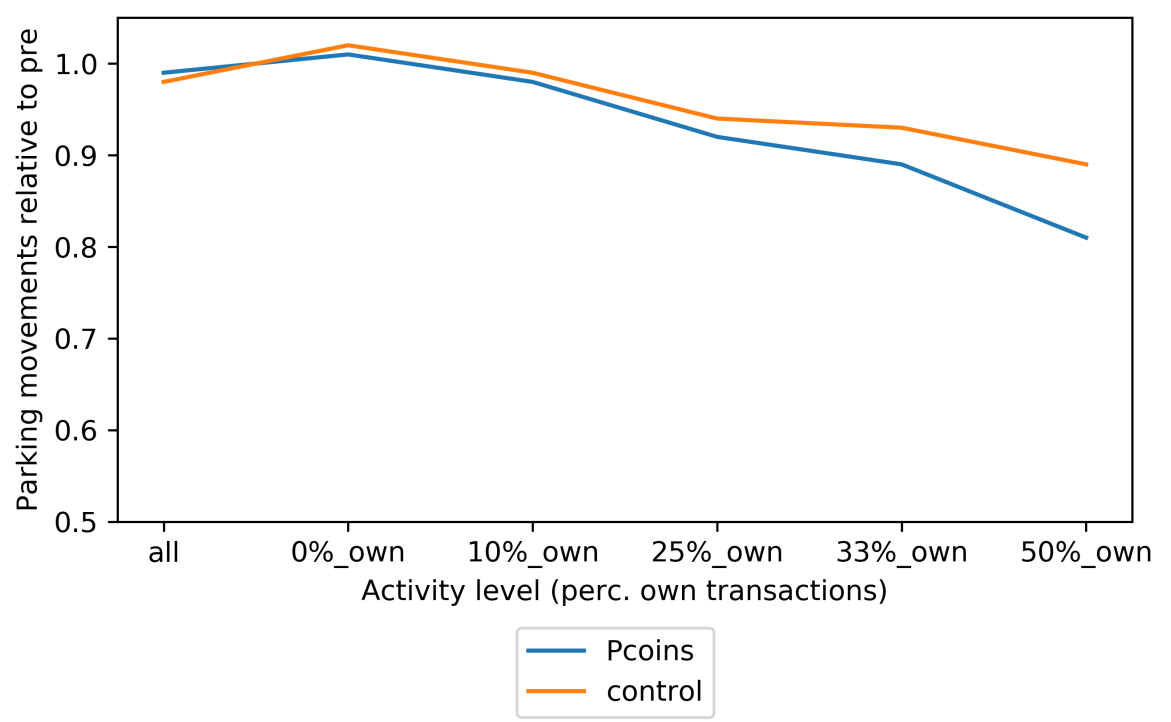

ticipants. The definition of active participants is in this case that at least one-third of the transactions must have been made by the participants themselves in order to qualify as active. The figure shows the parking movements of active and passive participants for each of the types of periods relative to pre-experiment weeks and adjusted for overall parking activity at the firm. The difference in activity between both types of users in terms of trades they made is considerable: with this definition, active participants traded on average 10.6 times during the entire experiment, while passive participants only traded 0.5 times in their four trading weeks.

The figure shows that active participants during the trading period (indicated as 'Pcoins') used the parking facilities between $80 \%$ and $90 \%$ of the level before the experiment (indicated by Pre). After the experiment (the post measurement), the number of parking movements was similar to that during the pre measurement, or even slightly higher. These differences are, however, not statistically significant. We investigate the response more rigorously in Section 4.2.

\subsection{Survey responses}

Many different questions were asked in surveys set out among participants before and after the experiment, and among non-participants. We discuss the interesting and important responses below, combining the responses of participants and non-participants in each figure. Those participating in the surveys were asked to rate statements on a 7 -point scale, ranging from totally disagree to totally agree. We calculated scores to generate each of the box plots. The qualitative responses have been translated to values ranging from -1 (totally disagree) to 1 (totally agree), with the seven points assigned values $-1,-2 / 3$, $-1 / 3,0,1 / 3,2 / 3$ and 1 . We do separate active and passive participants to see whether there are substantial differences between these groups. The definition of who is active and who is not that is used for these graphs is that at least one third of the total number of transactions should have been made by the participant, which is the same definition 
Figure 5: Response per period ( $\geq 33 \%$ own)

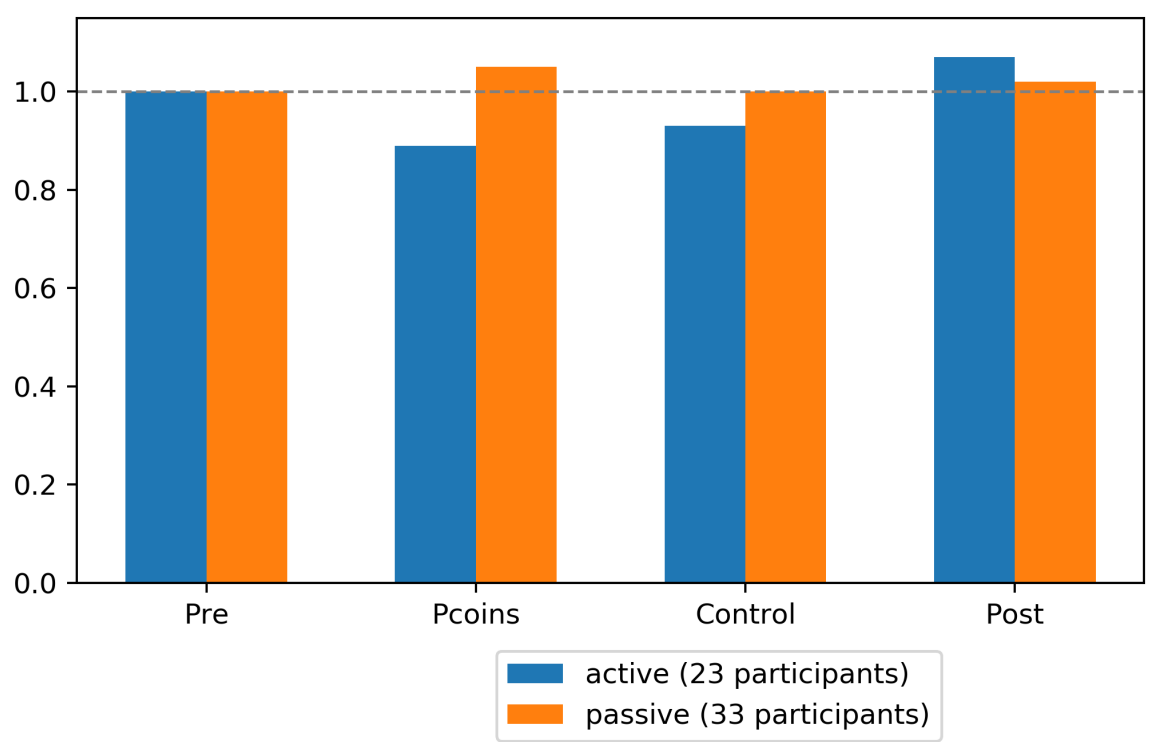

as is used for Figure 5. The horizontal orange line in each of the box plots represents the median value, while the coloured box itself represents the values between the 25th percentile and the 75th percentile. Mean scores are presented in de description below each graph.

Figure 6: Agreement with statements on perception of trading Pcoins

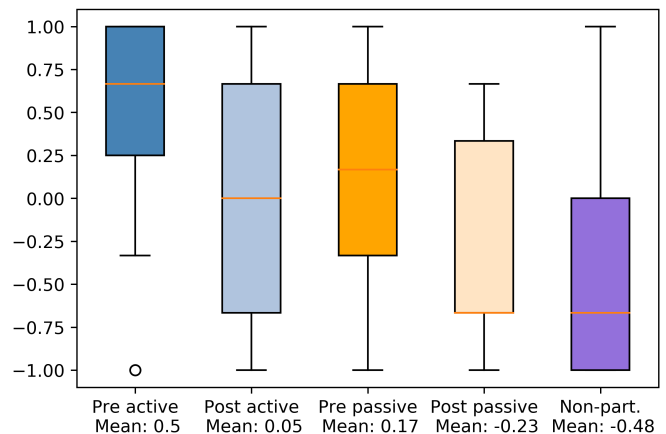

(a) 'Trading Pcoins seems fun.'

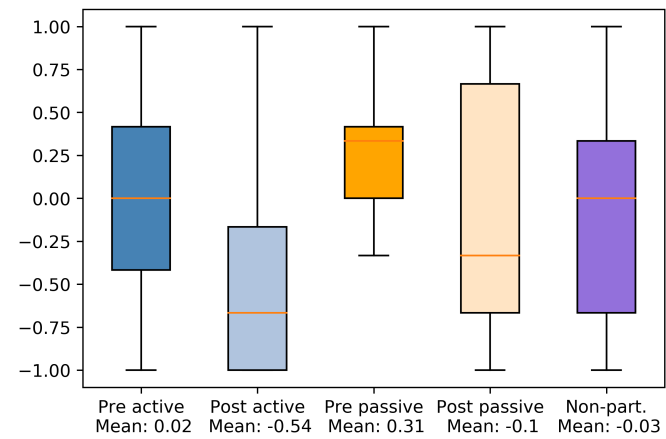

(b) 'Trading Pcoins seems difficult.'

Figure 6 displays box plots on the perception of trading Pcoins. As can be seen from (a) on the left, non-participants disagree relatively more and the median is to disagree with the statement that trading of Pcoins seems fun. Active participants are more positive about this than passive participants, both before and after the experiment, but both groups agree less with this statement in the post-experiment survey. The price pattern, with a price that continuously increased, may have played a role here. It is important here to emphasize that it is not intrinsically good if trading is "fun". Fun would presumably be associated with volatile prices and challenging trading strategies, which would have the downside of 
increasing transaction costs, creating possible advantages for more clever participants, and also providing incentives for behavioural responses in mobility that may not be justified by changing societal scarcity conditions and that therefore would be inefficient from the societal perspective. In other words, the maximization of "fun" in trading is not desirable in itself.

For the statement on trading being difficult, (b) in Figure 6, we see a shift to disagreement among the participants, indicating that trading is easier than anticipated.

Figure 7: Agreement with statements on Pcoins vs paid parking

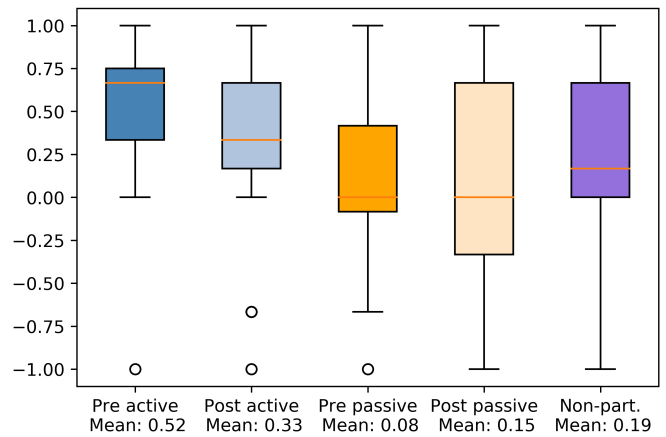

(a) 'I think a system with Pcoins will function better than paid parking.'

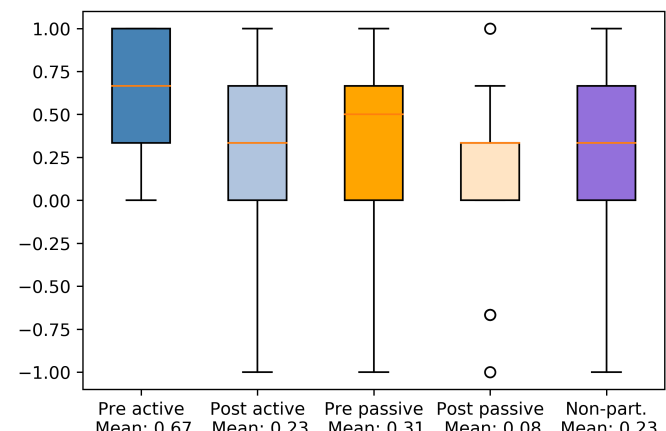

(b) 'I think a system with Pcoins will be more fair than paid parking.'

Figure 7 displays box plots on the comparison of tradable parking permits and paid parking. Interestingly, most of the active participants and non-participants agree with both statements and only very few disagree. The median response of passive participants is to be neutral towards statement that a system with Pcoins functions better than paid parking (a), with the spread in responses increasing after participation. We do see a small shift towards agreeing less among both active and passive participants for the statement on Pcoins being more fair than paid parking (b). However, the median for both groups is still positive, indicating that most of them still agree with the statement.

Figure 8: Agreement with statements on participation and Pcoin allocation

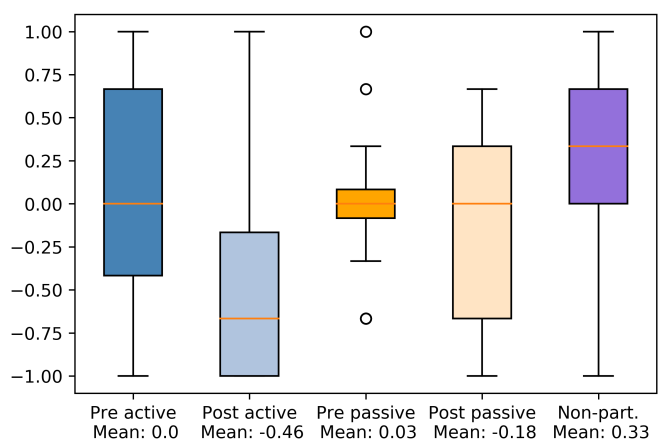

(a) 'Participation will take much time .'

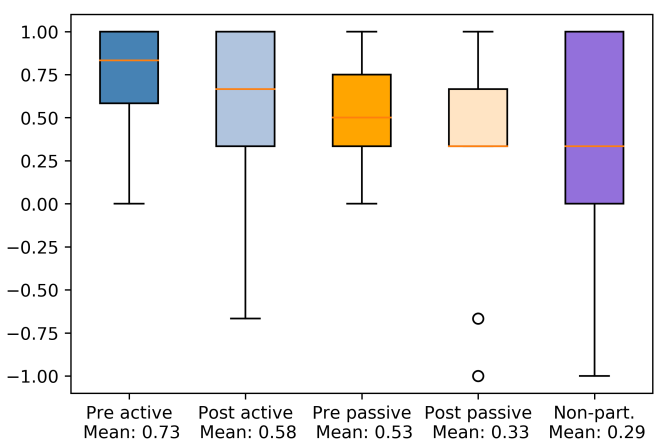

(b) 'Allocating permits based on number of working days is fair.'

Figure 8 presents box plots of the responses to the statement that participation is 
expected to take much time (a), and that an initial allocation of permits based on number of working days is fair (b). The former indicates that most non-participants think that participation does take much time, while most active participants disagree with this statement after participation and were neutral on this statement before participation. Box plot (b) on the right shows that almost all respondents agree that allocation based on number of working days is fair.

\subsection{Indications of rationality}

Besides the stated preference data obtained through surveys, we can also look at the permit use and trade data to get an idea of the degree of understanding and rationality of participants. One of the advantages of having had a price that increased throughout the experiment is that rational participants can be expected to respond more strongly to the incentive towards the end of the experiment. The simple reason for this is that they can earn more per avoided parking movement later in the experiment. Table 3 provides an overview of the response to the incentive for different selections of participants and for different moments of the experiment. It captures the difference between the average number of parking movements per week in (a selection of) the Pcoins weeks and the average number of parking movements per week in the control weeks. The first row of Table 3 shows that, when including all participants, the response to the incentive is close to zero. This is in line with the data in Figure 4. However, when looking at the active participants only, it becomes clear that these participants do react more strongly towards the end of the experiment. Comparing the first and the second column for the active participants makes clear that the decrease in parking movements in the last Pcoins period (weeks $5 \& 6$ of the experiment for participants in group A, and weeks $7 \& 8$ for those in group B) is larger than the average for the full experiment. Furthermore, the average response in the last week is larger than in the last period, as can be seen from comparing the second and third column. The average number of parking movements in the last control period for each of the participants does not deviate substantially from the overall average in the control periods, which indicates that these findings are driven by a change in behaviour during the trading period, i.e. a change in the response to the incentive. These data suggest at least a certain degree of rationality in terms of permit use. However, the displayed differences in responses are not significant. This could be due to a lack of power as a result of the small sample size, or because participants do not respond to the increase in price.

Table 3: Response to incentive

\begin{tabular}{lrrr}
\hline \hline & Full experiment & Last Pcoins period & Last Pcoins week \\
\hline All participants & 0.03 & -0.04 & -0.03 \\
Active $(\geq 33 \%$ own $)$ & -0.08 & -0.13 & -0.15 \\
Active $(\geq 50 \%$ own $)$ & -0.15 & -0.17 & -0.30 \\
\hline
\end{tabular}

NB: Changes in response are not statistically significant.

Besides this rational response in parking behaviour to the increasing price, participants can also be expected to adjust their trading behaviour after forming or adjusting their expectation of the price dynamics. In our case this means that they are likely to learn to expect the price to be higher towards the end of each trading period, which would make it rational to buy early in the week and sell later in the week. When looking at the 
ratio of purchases over sales and comparing the first and last trading week of each group, we do indeed see an indication of adjusted expectations and affected trading behaviour. As can be seen from Table 4, the ratio of purchases to sales was 1.0 for trades up until Tuesday, and 1.3 on Thursday and Friday in week 1 for group A, while being 1.2 and 0.2 respectively in week 6 of the experiment (their first and final trading week respectively). This suggests that participants adjusted their trading behaviour after learning about the price dynamics, and shifted purchases to the beginning of the week, when the price is relatively low, while postponing sales to the end of the week, when the price is relatively high. Trades of participants of group B show a similar albeit more extreme pattern, with a purchases to sales ratio of 2.1 up until Tuesday, and 0.7 on Thursday and Friday in week 3 , while in their last trading week (week 8) no sales were performed up until the end of Tuesday and no permits were purchased on Thursday and Friday. This also supports the notion of rational behaviour by participants.

Table 4: Purchases to sales ratios

\begin{tabular}{lcc}
\hline \hline & up until Tue & Thu Fri \\
\hline Group A - first week (wk 1) & 1.0 & 1.3 \\
Group A - last week (wk 6) & 1.2 & 0.3 \\
Group B - first week (wk 3) & 2.1 & 0.7 \\
Group B - last week (wk 8) & not defined & 0 \\
\hline
\end{tabular}

\section{Analysis and results}

The data we collected does not allow for estimation of detailed behavioural models with many covariates and interactions, as the number of participants in our experiment is too limited for that; i.e. we are constrained by the sample size to keep the models we estimate simple. However, these simple models can still provide valuable insights into the choice to participate, and the response to the incentive, which we both investigate in the section below.

\subsection{Modelling the choice to participate}

We use the survey responses of both participants and non-participants to model the choice to participate. As employees could voluntarily sign up to participate in our experiment, it is interesting to see whether we find a clear indication of self selection in our data. We model the choice to participate using linear probability models (LPM), providing us with estimates that are easy to interpret. ${ }^{4}$ These models have been estimated using the statsmodels package in Python.

To see whether there is an indication of self selection to participate among employees, we start with a benchmark LPM that only includes socio demographics to explain the choice to participate. In the next step we include attitudes, car use and car availability. For our LPM we consider the general following model:

$$
\text { participation }=\boldsymbol{X} \beta+\varepsilon,
$$

\footnotetext{
${ }^{4}$ We have also estimated logit models, as an alternative with a stronger theoretical foundation. Results from these logit models are not substantially different from those of the LPM.
} 
where participation is a vector of the dependent dummy variable (which equals 1 if an individual participated, and 0 otherwise), $\boldsymbol{X}$ is a matrix containing the selected exogenous variables, and $\beta$ and $\varepsilon$ are the parameter and error vectors respectively.

Table 5: LPM of participation - benchmark regressions

\begin{tabular}{lll}
\hline \hline & participation I & participation II \\
\hline Intercept & $0.2572^{* * *}$ & 0.1424 \\
age & $(0.0455)$ & $(0.2020)$ \\
& & 0.0003 \\
gender_undiscl & $-0.1737^{* * *}$ & $(0.0031)$ \\
& $(0.0611)$ & $(0.1804 * *$ \\
woman & & -0.0031 \\
& & $(0.0841)$ \\
inc_undiscl & -0.1001 & -0.0884 \\
& $(0.0818)$ & $(0.0923)$ \\
less2000 & & 0.1086 \\
& & $(0.2201)$ \\
between2k3500 & & 0.0227 \\
& & $(0.1014)$ \\
highly_edu & & 0.1101 \\
& & $(0.0940)$ \\
R-squared & 0.0243 & 0.0365 \\
R-squared Adj. & 0.0083 & -0.0221 \\
$\mathrm{~N}$ & 125 & 123 \\
$* * *, * *, *$ indicate significance at $1 \%, 5 \%$, and $10 \%$ \\
\multicolumn{2}{r}{ robust standard errors in parenthesis }
\end{tabular}

Results of the estimations of the model in equation 1 are presented in Table 5 . We include robust standard errors $\left(H C_{1}\right.$ in MacKinnon and White, 1985), which have undergone a degrees of freedom correction. Model I in this table represents the model with the highest adjusted $R^{2}$, conditional on only including socio demographics. Model II represents the model with all collected socio demographics. The $R^{2}$ of both models is very low, indicating that little of the variation in participation can be explained by the socio demographics. The main driver of this is that our sample of participants and non-participants are very similar in terms of socio demographics, which results in having little explaining power when modelling the choice to participate. The results show that those who do not want to disclose their gender (gender_undiscl) are less likely to participate. A possible explanation for this could be that this variable captures privacy concerns, which could make people hesitant to join. In general, the results show that, at least in terms of socio demographics, no clear self selection occurred in our sample, which is in line with the descriptive statistics discussed in Section 3.1. However, we cannot distinguish between having too little power to estimate the effects socio demographics have on participation, or the absence of self selection in terms of socio demographics. Having completed a higher education (highly_edu), being female (woman), age, or having a net family income below 2000 euro's a month (less2000) or between 2000 and $3500^{5}$ (between2k3500) all have no

\footnotetext{
${ }^{5}$ The reference category in terms of income is having a net family income above 3500 .
} 
significant effect on participation. Our results do indicate that, for example in terms of gender, there is not a very big difference in terms of how likely people are to participate (the $95 \%$ confidence interval for woman ranges from -0.170 to 0.163 , meaning that it ranges from women being approximately $16 \%$ less likely to participate than men to being $18 \%$ more likely).

We have also estimated LPM including variables on attitudes, car use and car availability. The results of two of these models are presented in Table 6 , where model I is the model with the highest adjusted $R^{2}$. Interpretation of these results requires more caution, as endogeneity issues (specifically simultaneous/reverse causality and omitted variable bias) pose a larger threat to the identification here. The results do show that participants more often indicate that they always have a car at their disposal (car_av) than non-participants. Furthermore, participants do on average agree more strongly with the statement that they think it is fun to trade in tradable permits (trade_fun) and that it is difficult (trade_diff). Our data does not contain significant associations between participation and how often people use their car (car), or the degree to which they agree that tradable permits function better (better)/are more equal (more_equal) than paid parking.

Table 6: LPM of participation - models containing attitudes

\begin{tabular}{lll}
\hline \hline & participation I & participation II \\
\hline Intercept & $-0.3058^{* * *}$ & $-0.3205^{* * *}$ \\
& $(0.1128)$ & $(0.1143)$ \\
better & -0.0245 & -0.0332 \\
& $(0.0239)$ & $(0.0339)$ \\
car & & 0.0042 \\
& & $(0.0204)$ \\
car_av & $0.1836^{* * *}$ & $0.1742^{* *}$ \\
& $(0.0555)$ & $(0.0719)$ \\
more_equal & & 0.0123 \\
& & $(0.0260)$ \\
trade_diff & $0.0407^{* * *}$ & $0.0403^{* *}$ \\
& $(0.0153)$ & $(0.0170)$ \\
trade_fun & $0.1118^{* * *}$ & $0.1099^{* * *}$ \\
& $(0.0185)$ & $(0.0188)$ \\
R-squared & 0.3414 & 0.3425 \\
R-squared Adj. & 0.3194 & 0.3091 \\
$\mathrm{~N} \quad 125$ & 125 \\
\hline$* * *, * *, *$ indicate & significance at $1 \%, 5 \%$, and $10 \% ;$ \\
\multicolumn{2}{r}{ robust standard errors in parenthesis }
\end{tabular}

\subsection{Modelling the behavioural response to tradable permits}

We also analyse the response to the incentive to reduce the number of times a participant parks during the week. We do so using the simple ordinary least squares (OLS) model:

$$
\text { response }_{i}=\beta_{0}+\beta_{1} \text { active_ }_{-} 0_{i}+\beta_{2} \text { pre }_{i}+\beta_{3} \text { pre_surv }_{i}+\varepsilon_{i},
$$

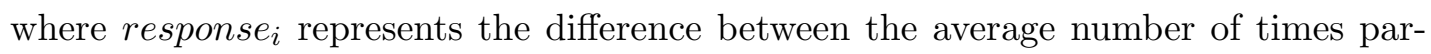
ticipant $i$ parked at the office per week in the control period versus the trading period; 
active $\_50_{i}$ is a dummy variable that equals 1 if at least $50 \%$ of transactions of participant $i$ were of their own doing (i.e. self made transactions as a percentage of the total number of transactions); pre $_{i}$ captures the average number of times a participant parked per week in the pre-experiment measurement; pre_surv $i$ is a dummy variable that equals 1 if the participant filled out the pre-experiment survey. Whether a participant fills out the pre-experiment survey could be predictive of their commitment to participate. This commitment can, however, change over time to no longer being committed to actively participate during the trading periods. In contrast, active_5 $50_{i}$ actually captures a specific degree of activity during the experiment, and additionally that participants will have observed the permit price at least a couple of times.

Table 7: OLS - response

\begin{tabular}{|c|c|}
\hline & response \\
\hline Intercept & $\begin{array}{l}0.0682 \\
(0.1810)\end{array}$ \\
\hline active_50 & $\begin{array}{l}-0.3030^{*} \\
(0.1743)\end{array}$ \\
\hline pre & $\begin{array}{l}-0.0050 \\
(0.0748)\end{array}$ \\
\hline pre_surv & $\begin{array}{l}0.1082 \\
(0.1758)\end{array}$ \\
\hline R-squared & 0.0388 \\
\hline R-squared Adj. & -0.0166 \\
\hline $\mathrm{N}$ & 56 \\
\hline
\end{tabular}

Estimation results of this model are presented in Table 7. We again use robust standard errors and have estimated multiple variations of the model of equation 2 , as we can change the threshold of own transactions for the active variable. We find similar results for each of the specifications, although the estimate for active_ $X$ becomes more insignificant at lower levels of self made transactions. As can be seen from the table, we do unfortunately not have much power to estimate these models, and we therefore cannot provide definitive proof of a significant response to the incentive. However, the results do suggest that indeed those who actively trade (a proxy for active participation) react to the incentive by parking less (although only so at the $10 \%$ significance level). The estimate of a 0.3 reduction suggests that participants park approximately $15 \%$ less. Interestingly, those who filled out the pre-survey do not seem to park less in the incentive period.

\section{Conclusion \& Discussion}

We have conducted an 8-week experiment with tradable parking permits for managing real parking behaviour among 65 participants. Our experiment took place at the headquarters of a Dutch company, ANWB, at the end of 2019 and beginning of 2020, before Covid-19 became a factor in commuting behaviour. We combine data on parking behaviour, trading behaviour and stated preference data from surveys among both participants and nonparticipating employees of ANWB. We analyse the choice to participate and find no clear 
evidence of self selection in terms of socio demographics. We do find associations between attitudes and the decision to participate. The collected parking data furthermore contain patterns that suggest that participants reacted rationally to the incentive of tradable permits, avoiding more parking movements as the price for permits increased. The trading data also show patterns that are in accordance with rationality, with participants moving towards buying additional permits early in the week as the price is still relatively low and selling them towards the end of the week when price was higher. Although these patterns are in line with what would be expected from rational participants, we do not have a large enough sample to establish their significance. We find suggestive evidence that those who participated actively in the trading of permits, reacted to the incentive by parking approximately $15 \%$ less. Furthermore, the results suggest that those who did not trade (or hardly traded) their permits did not park less in incentive weeks.

The experiment yielded a number of other relevant insights. First of all, the existence of a substantial number of passive participants has been shown to influence the price. Participants who do not actively participate in trading and do not adjust their parking behaviour ensure that the use of permits is relatively high. This has the effect of pushing up the price, and thus also affecting the market conditions active participants face. Even though this makes the trading less exciting, it increases the incentive for active participants to sell permits and change behaviour, in that way it is a desirable consequence if indeed the policy objective is to reach a certain overall goal for the entire group of participants. Nevertheless, it seems strongly advisable to work with alerts for passive participants when automated sales and purchases are being made, to increase - through improved transparency of the market and more complete information - the efficiency of the instrument. Furthermore, we speculate that part of the passive behaviour stems from the experimental design where there was a guarantee of a positive pay-off from participating. This may have given an incentive to just sign up and see at the end how much money was received. Structural applications of tradable permits, when being truly budget neutral at the aggregate level, will not have that feature.

The surveys show that taking part in the experiment requires less effort than most participants expected beforehand. This knowledge can be used in future experiments to recruit participants by communicating clearly about this. Another interesting finding is that tradable parking permits are seen by many of the participants as a better functioning and fairer alternative than the introduction of paid parking. How fair participants consider the initial distribution of permits to be can have an important effect on the support for the introduction of tradable mobility permits. A distribution based on the number of working days is seen as fair by most participants and non-participants alike. An concern here is that the fact that participants received a reward for participation in the experiment may have had an influence on their attitudes. However, it is unlikely that this is driving the results on the attitudes towards the comparison between tradable permits and paid parking, and the initial allocation based on number of working days, as these attitudes of participants are similar to those of non-participants (who were not rewarded).

Tradable permits could be used to allocate scarce parking space without government intervention. Our results indicate that the instrument is understood by participants and affects active participants' behaviour in the intended way in a mobility setting. Furthermore, tradable permits can be expected to more easily affect behaviour when applied to rush hour trips, as participants in such a tradable permit scheme face more alternatives to choose from when looking to adjust their behaviour than when applied to parking. The reason for this is that a time adjustment is sufficient to not use a permit in the former setting, while it is not for parking permits. 
One important caveat to our results is that ANWB employees are relatively highly educated, and may not be representative for the average road user in other respects as well, which has implications for the external validity of our results. Although our analysis does not suggest that socio demographics significantly affect the choice to participate in the experiment, some road users may still struggle to understand tradable permits and how to use them. Furthermore, ANWB employees may be relatively informed and interested in these types of measures and experiments, which might affect their behaviour and be correlated to responses to the survey questions. Future research among a larger (and more representative) group of road users will have to show whether our results also apply to the general population.

For future experiments with tradable permits, it is important to stimulate active participation within the tradable permit scheme. Although passive participation will likely be less common in applications where participants are not guaranteed a positive financial outcome for participation. Research into methods to further stimulate active participation (such as via notifications or surcharges on automatic transactions) is a relevant direction for future experiments. An important next step for future research is to conduct a large scale experiment with tradable rush hour permits, to test the effectiveness of tradable permits as a measure to reduce congestion. 


\section{References}

Akamatsu, T. and K. Wada (2017). Tradable network permits: A new scheme for the most efficient use of network capacity. Transportation Research Part C: Emerging Technologies 79, 178-195.

Arnott, R., A. De Palma, and R. Lindsey (1993). A structural model of peak-period congestion: A traffic bottleneck with elastic demand. The American Economic Review, $161-179$.

Aziz, H. A., S. V. Ukkusuri, and J. Romero (2015). Understanding short-term travel behavior under personal mobility credit allowance scheme using experimental economics. Transportation Research Part D: Transport and Environment 36, 121-137.

Bao, Y., E. T. Verhoef, and P. Koster (2019). Regulating dynamic congestion externalities with tradable credit schemes: does a unique equilibrium exist? Transportation Research Part B: Methodological 127, 225-236.

Brands, D. K., E. T. Verhoef, J. Knockaert, and P. R. Koster (2020). Tradable permits to manage urban mobility: market design and experimental implementation. Transportation Research Part A: Policy and Practice 137, 34-46.

Cohn, N. (October 2019). The TomTom Traffic Index: an objective measure of urban traffic congestion. Retrieved from https://www.tomtom.com/blog/road-traffic/ urban-traffic-congestion/ on March 18, 2021.

de Palma, A., S. Proost, R. Seshadri, and M. Ben-Akiva (2018). Congestion tolling-dollars versus tokens: A comparative analysis. Transportation Research Part B: Methodological 108, 261-280.

Geng, K., D. K. Brands, E. T. Verhoef, and Y. Wang (n.d.). Battling canteen queues: a field experiment with tradable rush hour permits among students. Currently under review.

Leape, J. (2006). The london congestion charge. Journal of Economic Perspectives 20(4), $157-176$.

Lindsey, R. and G. Santos (2020). Addressing transportation and environmental externalities with economics: Are policy makers listening? Research in Transportation Economics 82, 100872.

MacKinnon, J. G. and H. White (1985). Some heteroskedasticity-consistent covariance matrix estimators with improved finite sample properties. Journal of econometrics 29(3), $305-325$.

Nie, Y. M. (2012). Transaction costs and tradable mobility credits. Transportation Research Part B: Methodological 46(1), 189-203.

Tian, L.-J., H. Yang, and H.-J. Huang (2013). Tradable credit schemes for managing bottleneck congestion and modal split with heterogeneous users. Transportation Research Part E: Logistics and Transportation Review 54, 1-13.

Tian, Y., Y.-C. Chiu, and J. Sun (2019). Understanding behavioral effects of tradable mobility credit scheme: An experimental economics approach. Transport Policy 81, $1-11$. 
Verhoef, E., P. Nijkamp, and P. Rietveld (1997). Tradeable permits: their potential in the regulation of road transport externalities. Environment and Planning B: Planning and Design $24(4), 527-548$.

Vickrey, W. (1973). Pricing, metering, and efficiently using urban transportation facilities. Highway Research Record (476), 36-48.

Wang, X., H. Yang, D. Zhu, and C. Li (2012). Tradable travel credits for congestion management with heterogeneous users. Transportation Research Part E: Logistics and Transportation Review 48(2), 426-437.

Xiao, F., J. Long, L. Li, G. Kou, and Y. Nie (2019). Promoting social equity with cyclic tradable credits. Transportation Research Part B: Methodological 121, 56-73.

Xiao, F., Z. S. Qian, and H. M. Zhang (2013). Managing bottleneck congestion with tradable credits. Transportation Research Part B: Methodological 56, 1-14.

Yang, H. and X. Wang (2011). Managing network mobility with tradable credits. Transportation Research Part B: Methodological 45(3), 580-594. 